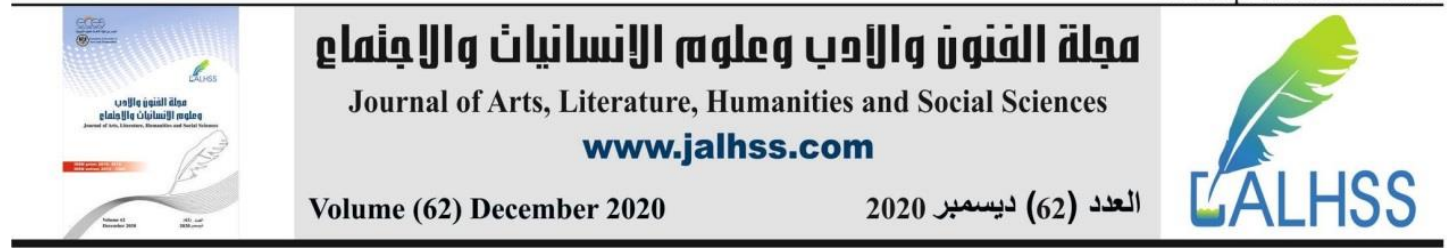

\title{
The Effect of the Gracha Model on Developing the Cunning Thinking of the Students of the Technical Medical Institute in Physiology
}

\author{
Assist. Prof. Miaad Nadhum Rasheed \\ Technical Medical Institute - Middle Technical University - Iraq \\ Email: meiadnathem@gmail.com
}

\begin{abstract}
The current research seeks to identify the effect of the Gracha model in developing skilled thinking among students of the Technical Medical Institute in Physiology, and to achieve the goal and hypothesis of the research, the researcher adopted the experimental method with partial control through two experimental and control groups. The researcher identified the research community with students of the Technical Medical Institute at Baghdad University, and due to the small size of the community, it was considered a community sample for the current research. In order to collect data and information and ensure the efficiency of the experimental design used, the researcher carried out a set of psychometric procedures, and after completing the application of the experiment, the researcher reached the following results:

1. There is no clear effect of (Gracha) model on the development of skilled thinking among students of the experimental group in physiology among students of the medical institute.

2. The experimental group that was studied on the Gracha model outperformed the control group that received the scientific material by the lecture method of Physiological Subject at the Technical Medical Institute.
\end{abstract}

Keywords: Gracha Model, Cunning Thinking, Technical Medical Institute, Physiology. 


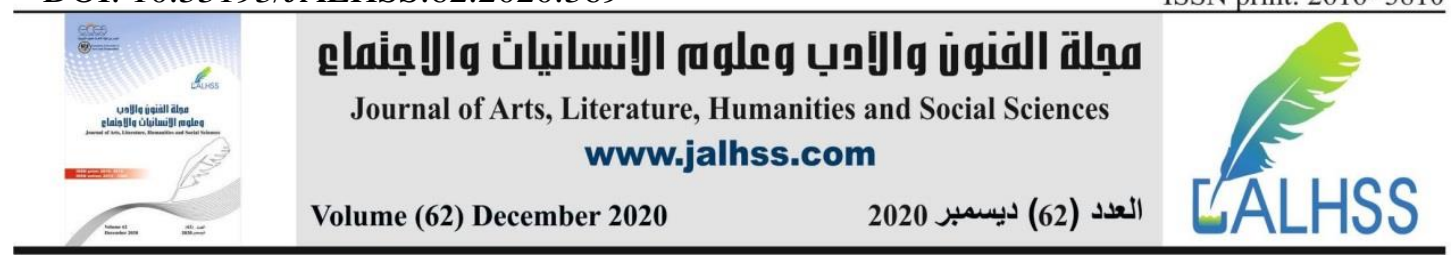

\section{Introduction}

The success of $\mathrm{Gm}$ for me from education but it depends on a set of the most important elements of the teacher who has a set of skills in the field of models and teaching methods that depend on modern teaching of the learner gives enough space to express their needs from the interest that appeared recently in the fashion of learners and the tendencies that affect how they acquire For knowledge, a set of educational models have emerged that try to divide the learners into categories according to the social pattern (introvert, extrovert) ... etc. . In order to meet cognitive needs based on personality traits. Among these models is the model (Jerasheh, 1974), which divided learners into multiple departments and styles. Each method has a way of acquiring knowledge, and the teacher must be aware of this classification in order to deal with students and their requirements. There is no doubt that thinking is one of the important mental features that modern educational trends focus on in order to understand the mental and personal aspects of the educational process. There is no doubt that the development of thinking, especially accurate thinking, as it represents the wide range of thinking skills needed in education, is crucial.

\section{First: the research problem}

The curriculum of the Department of Physiology at the Technical Medical Institute carries with it multiple thinking patterns, and what the researcher observed from polling a sample of the department's teachers with a clear weakness in developing certain patterns of thinking among students is due to many reasons, including: The traditional teaching method used in most cases. It can also be said that there is a difference between Technical Medical Institute students in their learning styles and is reflected in the different levels of intelligence or thinking patterns that they possess, where theoretical frameworks appear that can be performed. We notice the difference in the performance of students and their thinking that can be attributed to the teaching method, and this means that using one method of teaching is not sufficient even if this method is modern and sophisticated. Rather, it is necessary to adopt more than one method that depends on the type of education that suits the students, and this is available in modern learning models, including the model (Gracha, 1994), and since then the teaching researcher at the Technical Medical Institute at Baghdad University has noticed clear differences in thinking skills, including (Gracha, 1994). Smart thinking), and the study will try to answer the following question: What is the effect of the Gracha model on the development of cunning thinking among students of the technical department? Medical Institute in Physiology?

\section{Second: The importance of research}

The use of modern models in teaching the subject leads to the success of the teacher in his work by ensuring that students continue to interact with him and the material, and this is done through social discussions between the teacher and his students on the one hand. And among the students and their colleagues on the other side (Al-Dhahr, 2009: 40) the subject of individual learning methods has aroused the interest of many scholars and researchers as an urgent necessity to improve and develop the 


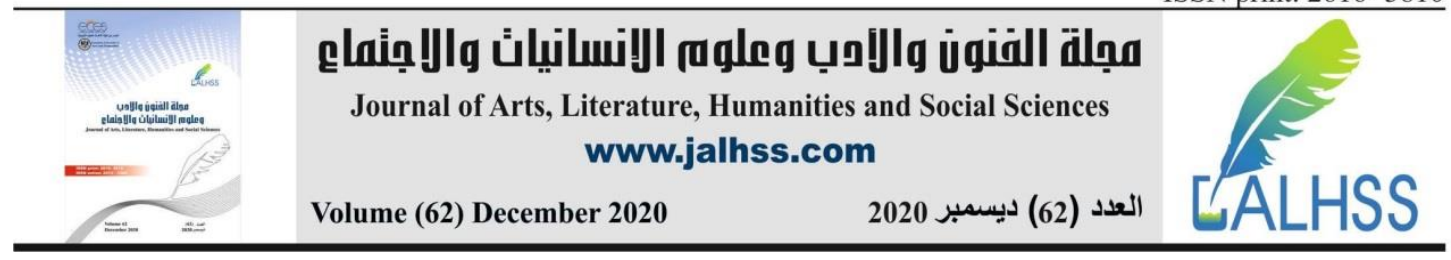

educational process, in addition to its role. In helping teachers provide an educational environment and diversifying teaching methods in line with methods of preparing students for information (Al-Shawqi, 2004: 264). In order to develop students' thinking, modern methods, strategies and models of institutionalization must be used in addition to their diversity during one semester in order to match the clear differences between students, and this is what seeks to model (Jerasha, 1974). $g$ is an essential element in the information structure of the individual, and this element is distinguished from the rest of the cognitive elements because it is more complex, flexible and deep than others, and that seeking to employ thinking in the learning process contributes to transformation. From an inactive process to an active and efficient currency (Aziz, 2015: 3). Intelligent thinking is not just a set of mental skills that nature imposes on the individual through maturity and growth, but it needs structured learning through structured teaching models that seek to develop it in the individual with the aim of reaching him as far as possible. (Al-Khalili, 2005: 30). In this regard, (Al-Saffar, 2011) indicated that smart thinking contributes to the development of an individual's experiences and skills, in contrast to the usual daily thinking that does not contribute to the development of these skills (Al-Saffar, 2011). :( 11). The importance of the current research can be summarized in the following points:

1. The scarcity of previous Arab and local studies that dealt with the effect of the Gracha model on the teaching of physiology

2. Shedding light on one of the modern learning models that considers the learner the focus of the educational process and explaining teaching methods and procedures.

3. Helping teachers choose appropriate learning methods for the learner

4. Shedding more light on learners' patterns and ways of thinking that can be developed through modern learning models.

5. The importance of smart thinking as it is one of the thinking skills included in the physiology curriculum, and the fact that the curriculum is weak in developing these skills, it was necessary to pay attention to the teaching method that contributes to raising the level of intelligence. Thinking.

\section{Third: The aim of the research}

The current research seeks to identify the effect of the Gracha model on developing the skillful thinking of students of the Technical Medical Institute in Physiology.

\section{Fourth: the research hypothesis}

The current research is based on the following null hypothesis: There are no statistically significant differences between the mean of the experimental group that was studied using the (Gracha) model and the mean of the control group that was studied using the method of the lecture in physiology. Of course in another application.

\section{Fifth :Research limits}

1. Human Limit: Students of the Technical Medical Institute 


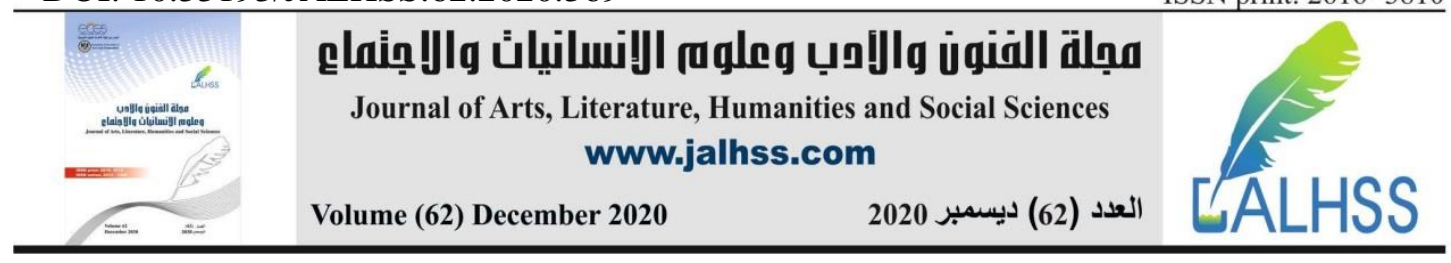

2. Time limit : the academic year2021-20-20

3. Spatial Limit: Technical Medical Institute

\section{Sixth :Defining terminology \\ First: The Gracha model (Gracha model) \\ Known by:}

1. (1974), Gracha: It is one of the learning models that focus on the social interaction between students and the teacher or students and their colleagues in order to accomplish a specific educational task, and this model also takes into account the differences in the learning styles of the learners in addition to focusing on the level of their group towards the topic (1974). : 213, (Gracha

2. (Baykul et al, 2010): One of the teaching models that focus on the thinking patterns of learners and their impact on the acquisition of scientific material, as this effect can be divided based on the learners 'attitudes towards the material, the teachers' views in addition to their reactions about the teaching methods used (Baykul et al, 2010: P59 (the researcher adopts a definition) 1974 Gracha A theoretical definition of current research.Definition of procedural: specimen depends on dealing with students according to the patterns of thinking and academic content commensurate with this style in order to reach the highest level of achievement possible.

\section{Second :subtle thinking Smart thinking}

\section{Knew:}

1. (Olive, 2003) is this type of thinking that is represented through processes of comparative thinking, visualization and inference, and higher thinking processes such as problem-solving, decision-making, and metacognition (Zaitoun, 2003, 86)

2. (2009, Arthur \& Bena) is "a type of intelligent behavior that leads to productive behaviors to confront a dilemma, and it refers to the use of intelligent behavior when an individual does not know the most appropriate answer or solution" (Arthur and Bina (2009, p: 27).

Theoretical definition: The researcher adopted a definition (Arthur and Bina 2009) a theoretical definition of the current research.

Procedural definition: the total score obtained by the respondent on the critical thinking scale used in the current research.

Third: Physiology: The researcher can define the definition: "It is that the material studies the sciences and functions of living organisms. The specialized knowledge in physiology studies how the body works, which means the physiology of animal and plant lavender. Physiology studies the activities of physical life. Whether on the level of the whole organism or part of it, or at the level of the cell or part of it, the goal of physiology is to understand the meaning of life.

\section{A theoretical framework and previous studies}

First: a theoretical framework

\section{The Gracha model of learning}

Educators try to discover the methods that students use during education and generalize it with information in general, which leads to its use in improving and developing the process in education, and this approach has led to interest in and 


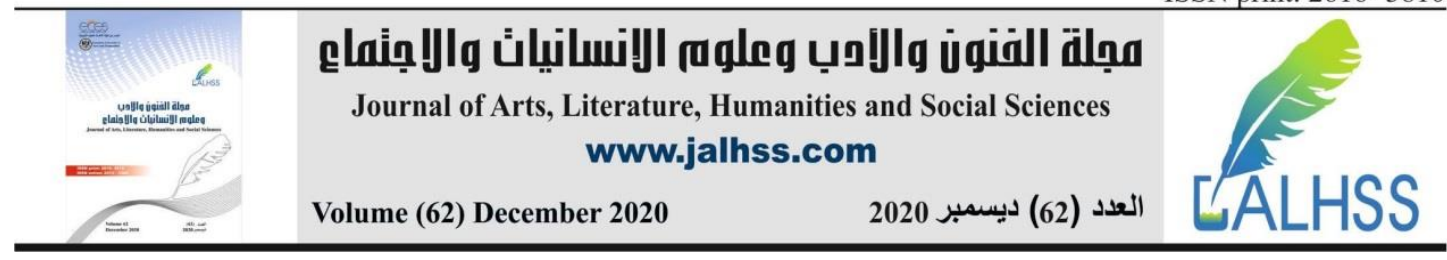

disclosure of different learning methods. (Jingle, 2013: 4) Studies in the field of learning styles confirm that a teacher's focus on a single teaching method in school learning can have an impact. It may be positive for some students when the teaching method is compatible with their teaching style, and the effect is negative for other students when the method does not match their teaching method with the teaching method of others (Al-Harbi, 2012: 260). The model (Jracha, 1974) is one of the richness of cognitive models that has been presented as an explanation of individuals' learning styles, which provides a model for cognitive patterns of learning, and which provides properties that can be used to measure these.Methods for learning are not distinguished in the learning environment. This model can be seen as a measure of the level of students who maintain their motivation towards learning (1996: 59, Sanchez). This unit focuses on measuring students' performance in their social interaction and it shows how students interact with their teachers; With the rest of my classmates, and through the task at hand, the model also focuses on the type of hat learning method the student prefers in the classroom, which is important if we take into account the needs of students in the classroom (1996: 59, Sanchez). The scale (Jracha, 1974) supports social interaction that consists of three dimensions $t$ related to social interaction in the classroom: 1. Learners' attitudes and learning memory about learning. 2. Learn the opinions of their teachers. 3. Learner's notes about the teaching methods used (Baykul et al, 2010: P59) some researchers have indicated that the (Gracha, 1974) model differs from other models because it depends on students 'response to the activities of the master class rather than providing a general evaluation of personality or perceptual features. (Kumar, Kumar \& Smart, 2004: P535; Montgomery \& Groat, 1998: P5

\section{Classification of learners in the Gracha model}

This model illustrates how learners interact in the classroom, where three contradictory learning styles have been developed: (dependency / independence), (competitive / cooperative) (avoidant / participatory) and there are six patterns of students' response, which are (atrophy, atrophy). (2008: 34)

1. Dependencies: They view the teacher and colleagues as a source of guidance and prefer a strong personality to tell them what to do with it, and they depend on others to learn for this. They depend on others in the learning process.

2. Independents: they prefer to learn on their own instead of working and thinking with others, but while listening to others.

3. Competitive: they regard learning as a losing confrontation, and learning motivates them to excel over others, that is, to show their best performance and distinguish them from their peers, and they always prefer and want to be praised for their academic achievements among their colleagues.

4. Collaborators: they prefer learning information through sharing and cooperation with colleagues and their mentor, and prefer lectures with small group discussions and group projects.

5. Avoidance: they are characterized by a lack of active participation in the classroom, lack of interest in learning, and lack of motivation to attend the lesson, and sometimes they are confused in class activities. 


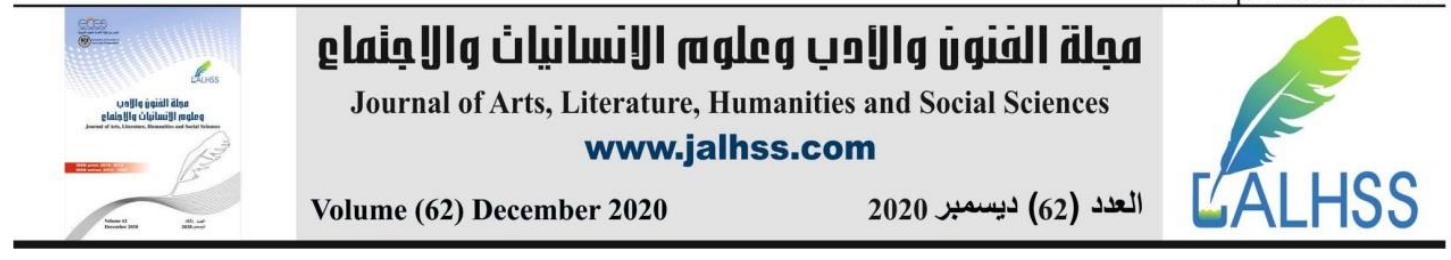

6. Participants: they view learning as an opportunity to interact with others. They are aware of their school environment, are eager to do classwork as much as possible, and have a desire to meet the teacher's expectations. Ideally, each person may possess some of all of these patterns, and have a balance in all learning styles, and some of them may lean toward one or two of these patterns as well, as they are likely to change these preferences, especially when faced with new experiences. (Gracha, 1996: 54)

\section{Smart thinking}

Students practice a variety of thinking skills, ranging from simple to complex. Perhaps all of this falls under the elements of hidden behavior. Scientists have described the person who owned it as a skilled thinker. Intelligence means speed and smoothness, or the motor skill that usually distinguishes the fingers, hand and arm in accomplishing some tasks, and it may sometimes mean skill in dealing with people, dealing with difficult matters, and getting out of problems (Al-Hijazi, 2012, p .: 173). Intelligent thinking achieves a set of results for individuals that can be explained as follows:

1. The tendency of people to think carefully and cautiously about the problems they face in different life situations, so that they learn to think intelligently and take automatic decisions at times.

2. Individuals are able to recognize appropriate opportunities to use certain behavior patterns better than others.

3. They prefer to choose productive, intelligent and rational behavior patterns rather than other less productive patterns.

4. Individuals possess the ability to implement thinking patterns to face problems, that is, possess the basic skills and abilities to implement intelligent thinking in specific situations.

5. Individuals are keen to adhere to deep and sober thinking and to constantly learn new skills and knowledge (Nofal and Muhammad, 2008: 83)

In order for students to be productive and thinkers, teachers must follow a purposeful, planned and thoughtful educational strategy aimed at developing higher-order thinking skills, and this only occurs through appropriate teaching methods that they also follow through curriculum development. While training in Good Thinking, it helps students to be more accurate and to be able to work on problem solving objectively so that they can participate in free discussions (Al-Suroor, 2005, p: 201). So, accurate thinking is what happens to achieve learning in the content areas, and habits of mind, which are implementable mental processes and organizational procedures that drive the use of intelligent thinking in ways that display mental behaviors with a broad and fruitful relationship, such as perseverance, openness, flexibility, control of emotions and the pursuit of accuracy in behaviors. (2008: 2-3, Swart).

Smart Thinking Tools Symbols, shapes and signs

Indicates Mangel, $2004 \mathrm{He}$ indicated that there are a variety of smart thinking tools that a person uses in the activity of smart thinking, namely: 


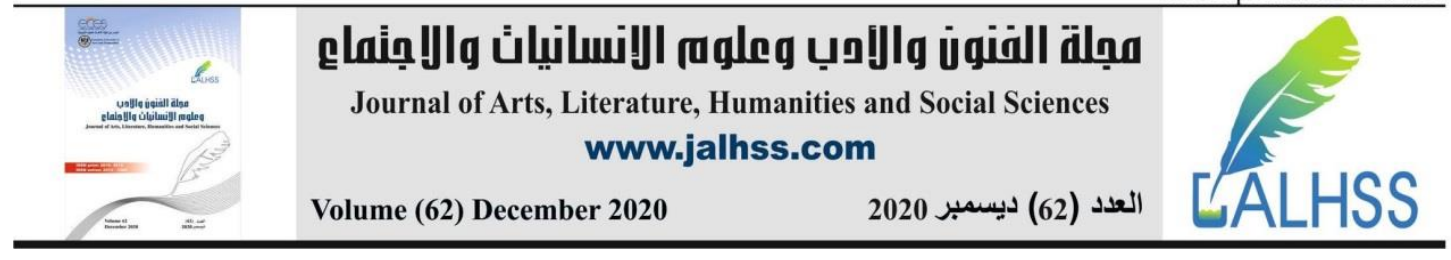

1. Symbols, shapes and signs:They are the tools of human thinking that refer to physical and intangible things, and a symbol is everything that acts on behalf of a thing or takes its place in its absence, or refers to it, and some images such as traffic lights are symbols and letters. Words, numbers, shapes and images are all symbols that usually express meanings and concepts, and the more clarity of expression this leads to the enhancement of thinking and effectiveness (Mahmoud, 2006: 73)

2. Imagination: It is a mental process related to creating mental images of objects, topics, or events, and helps to store information in memory on the one hand and retrieve information from memory on the other hand, and it is not just a process. . Retrieving information, but reorganizing what the individual learned, analyzing and using it in this presentation, especially if he is facing a situation that requires solving a problem or inventing something new, and it should be noted that the past can be remembered in various ways, including (mental images, implicit speech, language, etc. (Mental Perception) (Atia, 2010: 46)

3. Concepts: A large group of previous experiences is summarized in a previous idea or in the sense of distinction, generalization and classification, and thinking cannot occur without going through these things (Yusef, 2011: 45)

4. Language: It is a system of symbols and rules that allow an individual to communicate with others. In order to be able to address others, he must think about expressing what he wants or what is going on in his mind. One of the most effective ways to implement the thinking process (Al-Ashkar, 2011: 31)

5. Brain functions: The functions of the brain are thinking, feelings and emotions, as it is the frontal area in which the process of thinking, imagining, speaking, writing and movement takes place, and in the middle of the brain there is. The area of hearing, interpreting sensations and giving them meaning, and in the posterior region of the brain the nervous system performs its function to interpret visual sensations (Salem, 2012: 28)

6. Muscle activities: In many cases, thinking causes a group of muscles in the body to move. When an individual thinks about a particular word, we observe simple muscle responses that are similar to the movements the individual makes when uttering out loud. Mengele confirmed that studies indicate a relationship between muscle activities and individual thinking, that is, when an individual thinks, muscle contractions increase and vice versa (Nouval and Rimawi, 2010: 29)

\section{Second :Previous studies}

Given the interest of the current study in the Gracha Model of Learning Styles, the researcher will limit himself to referencing previous studies that have used this model. A study (Khaled et al., 2013: 6) was conducted on Malaysian high school students with the aim of investigating the effect of learning styles on academic student achievement in general and literary majors. The study used the Gracha Scale of Learning Styles, as well as students' achievement scores. The results indicated that most students prefer approved and then collaborative methods among scientific and literary students, regardless of the level of students 'achievement, as there are no differences in learning methods attributed to a specialist (scientific / literary). Except for the method of avoiding learning. There is no statistically significant relationship 


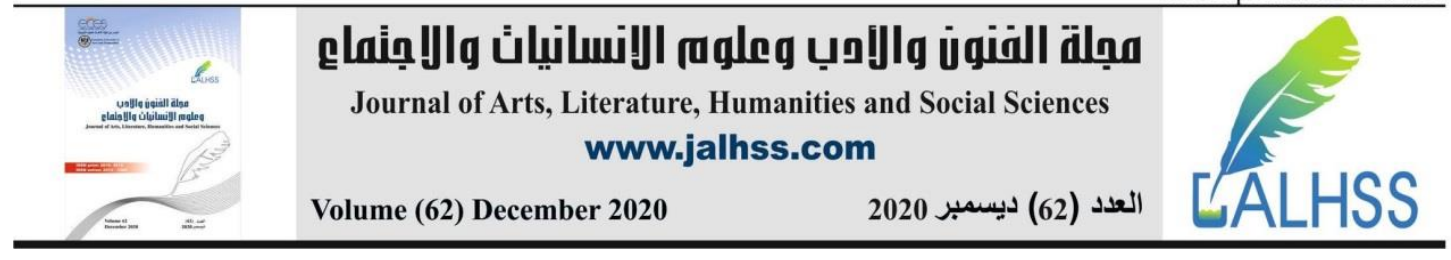

between learning styles as a whole and educational achievement except for the method of avoidance, and the study showed that the sample characteristics amounted to $(89 \%)$ of those with low achievement $(73 \%)$ of the average achievement. The study (Khan \& Iqbal, 2016: P 29) examined the effect of distance learning styles of master's degree students in a Pakistani university through the Gracha scale. The results of the study indicated that students used Gracha's learning styles in general, and the study found that the most common method of education among the study sample is the learning method (cooperative, participatory, independent, and competitive). The less common method is pleural. (Isaac and Awang, 2017) conducted a study on the relationship of learning styles (200) Malaysian students to their achievements in history using the GrachaA scale and grades in this subject. The results indicated an increase in all learning styles. The least of which is the avoidance method, which indicates that students use all these methods in the study of history, and the study also indicated that there are differences in learning styles according to gender, and there are no statistically significant correlations between learning styles and student achievement in the history subject, except for the extremely weak correlation. Approved learning style.

\section{Commentary on previous studies}

The researcher employed previous studies in some aspects of the research:

1. Crystallize the research problem and its importance

2. Define some terms

3. Identify previous studies

4. Experimental design and equivalence of the sample

5. Compare the results of the current study with previous studies

\section{Research Procedures}

This chapter describes the methods used in the research to choose the appropriate experimental design, determining the research population, the method for selecting the sample, the extent of equivalence, the steps for preparing the research tools, and the methods used to verify them. Validity and stability, in addition to other research procedures.

\section{Design of experimental research}

The process of selecting an experimental design is considered one of the simplest steps for the researcher, because it saves him time and effort and how he can achieve the necessary results (Al-Zobaie, 1981, p.102) (Odeh and Malakawi, 1987. P.167). Therefore, the researcher chose an experimental design with partial control, as it included Two groups, the first experimental group studies the material according to the (Jarash) model, and the other is a control group that studied in the usual way. . At the end of the research experiment, you will be subjected to a test that measures the thinking skills of the sample members, and Table (1) illustrates this.

Table (1) the experimental design of the research

\begin{tabular}{|c|c|c|}
\hline Dependent variable & Independent variable & the group \\
\hline \multirow{2}{*}{ Smart thinking } & The Gracha model & Experimental \\
\cline { 2 - 3 } & - & Control \\
\hline
\end{tabular}




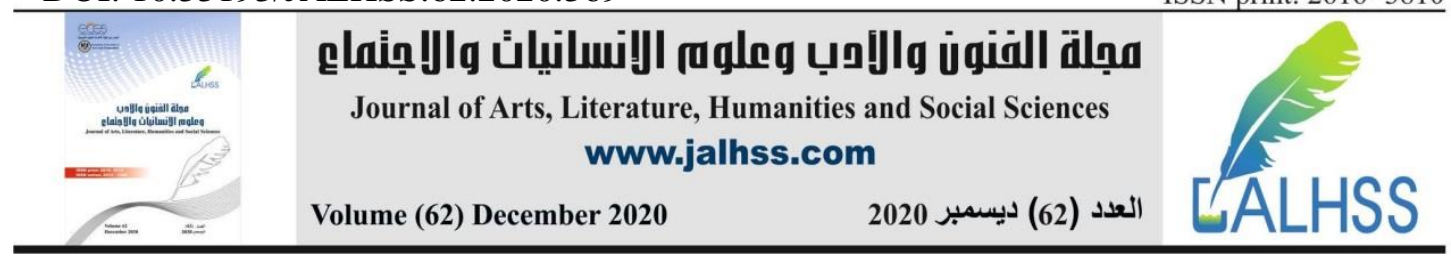

Second: the research community

The study population is any known group of objects, people, or accidents, and it is the comprehensive group from which samples are selected (Odeh and Al-Khalili, 1988: 171). The research community consists of technical medical institute students who receive physiognomy.

\section{Third: the research sample}

The sample is defined as a part of the community in which the study is conducted, and it is selected according to certain criteria to be representative of the research environment (Daoud and Abdel-Rahman, 1990, p. 67). He (Al-Zaytoon, 1999) defined it as a group of individuals drawn in a certain way from the original community to study it (Al-Zaytoon, 1999, p. 17). The researcher selected a sample of students of the Medical Institute, where the researcher selected (40) male and female students, they were randomly divided into two groups, the first and second experimental groups, equal control, and the following table shows the research sample:

Table (2) shows the sample members according to the two research groups

\begin{tabular}{|c|c|c|}
\hline the total number & Future variable & the group \\
\hline 20 & The Gracha model & Experimental \\
\hline 20 & Present pain & Control \\
\hline
\end{tabular}

\section{Fourth: Equivalence of the two research groups:}

Before conducting the experiment, there are a set of variables that the research sample must undergo an equation and equation process between them, as neglecting them may affect the accuracy of the results, and these variables are available based on previous studies, and after reviewing the number of previous studies and research and the research methodology and objectives, the researcher reached A number of variables in which the experimental and control groups can be equivalent, namely (estimated age in months, intelligence through the Raven Matrix test consisting of (60).) Four-alternative items, in addition to preparing the smart thinking scale consisting of 30 items.

* Equivalence in Age: The researcher (T) used two independent samples in order to identify the equivalence of the experimental and control groups in the age variable, and the results appear in the following table:

Controversy (3) parity between the two groups in chronological age

\begin{tabular}{|c|c|c|c|c|c|c|c|}
\hline \multirow{2}{*}{ Judgment } & \multirow{2}{*}{$\begin{array}{l}\text { Indication } \\
\text { level }\end{array}$} & \multicolumn{2}{|c|}{ Value -t- } & \multirow{2}{*}{$\begin{array}{l}\text { standard } \\
\text { deviation }\end{array}$} & \multirow{2}{*}{$\begin{array}{c}\text { Arithmetic } \\
\text { mean }\end{array}$} & \multirow{2}{*}{$\begin{array}{c}\text { the } \\
\text { number }\end{array}$} & \multirow{2}{*}{ the group } \\
\hline & & Tabular & Calculated & & & & \\
\hline \multirow{2}{*}{$\begin{array}{c}\text { Not a } \\
\text { function }\end{array}$} & \multirow{2}{*}{0.05} & \multirow{2}{*}{2.02} & \multirow{2}{*}{0.674} & 2.207 & 227.15 & 20 & Experimental \\
\hline & & & & 2.909 & 226.60 & 20 & Control \\
\hline
\end{tabular}

It is noticed through the previous table that both groups are equal in the estimated chronological age in months because the calculated value is smaller than the tabular value, which indicates that the two groups are equal. 


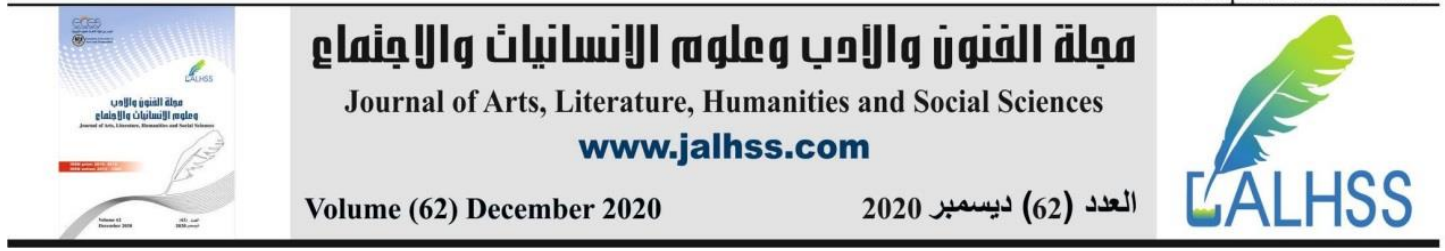

*Parity in the IQ test

The researcher used (T) for two independent samples with the aim of identifying the equivalence of the experimental and control groups in the variable of intelligence after using (Raven) test for series matrices consisting of (60) items, and the results are shown. In the following table:

Table ( 4 ) Parity between the two groups in IQ test

\begin{tabular}{|c|c|c|c|c|c|c|c|}
\hline \multirow{2}{*}{ Judgment } & \multirow{2}{*}{$\begin{array}{c}\text { Indication } \\
\text { level }\end{array}$} & \multicolumn{2}{|c|}{ Value - $t$ - } & \multirow{2}{*}{$\begin{array}{c}\text { standard } \\
\text { deviation }\end{array}$} & \multirow{2}{*}{$\begin{array}{c}\text { Arithmetic } \\
\text { mean }\end{array}$} & \multirow{2}{*}{$\begin{array}{l}\text { the } \\
\text { number }\end{array}$} & \multirow{2}{*}{ the group } \\
\hline & & Tabular & Calculated & & & & \\
\hline \multirow{2}{*}{$\begin{array}{l}\text { Not a } \\
\text { function }\end{array}$} & \multirow{2}{*}{0.05} & \multirow{2}{*}{2.02} & \multirow{2}{*}{0.482} & 2.60 & 45.95 & 20 & Experimental \\
\hline & & & & 0.988 & 45.65 & 20 & rol \\
\hline
\end{tabular}

It is noticed through the previous table that both groups are equal in the IQ test because the calculated value is smaller than the tabular value, which indicates that the two groups are equivalent.

\section{* Equivalence in the Skilled Tribal Thinking Scale}

The researcher used the( $\mathrm{T}$ )For two independent samples in order to identify the equivalence of the experimental and control groups in the variable of smart thinking after using a scale consisting of (30) items, and the results are shown in the following table :

Controversy ( 5 ) The parity between the two groups in the smart tribal thinking scale

\begin{tabular}{|c|c|c|c|c|c|c|c|}
\hline \multirow{2}{*}{ Judgment } & \multirow{2}{*}{$\begin{array}{c}\text { Indication } \\
\text { level }\end{array}$} & \multicolumn{2}{|c|}{ Value -t- } & \multirow{2}{*}{$\begin{array}{l}\text { Standard } \\
\text { deviation }\end{array}$} & \multirow{2}{*}{$\begin{array}{l}\text { Average } \\
\text { arithmetic }\end{array}$} & \multirow{2}{*}{$\begin{array}{l}\text { the } \\
\text { number }\end{array}$} & \multirow{2}{*}{ the group } \\
\hline & & Tabular & Calculated & & & & \\
\hline \multirow{2}{*}{$\begin{array}{l}\text { Not a } \\
\text { function }\end{array}$} & \multirow{2}{*}{0.05} & \multirow{2}{*}{2.02} & \multirow{2}{*}{1.630} & 1.348 & 88.15 & 20 & $\begin{array}{c}\text { Experimen } \\
\text { tal }\end{array}$ \\
\hline & & & & 0.935 & 87.55 & 20 & Control \\
\hline
\end{tabular}

It is noticed through the previous table that both groups are equal in the scale of skilled thinking because the calculated value is smaller than the tabular value, which indicates that the two groups are equal.

\section{Fifth: Skilled Thinking Scale}

The researcher adopted the scale (Arthur and Bina 2009): a theoretical definition of the current research, and the scale consists of (84) items distributed on the following areas: (perseverance, controlling recklessness, listening to others with understanding and compassion, and cooperation in thinking (thinking)). Likewise), flexible thinking, reflection on thinking, checking accuracy and correctness (struggle for accuracy), finding a sense of humor, past experience and applying it to a new situation, permanent readiness for continuous learning, perception, innovation and renewal, questioning and posing problems, collecting data with all the senses, Take responsible risks). Due to the length of the scale, the researcher shortened the scale to (30) items. 


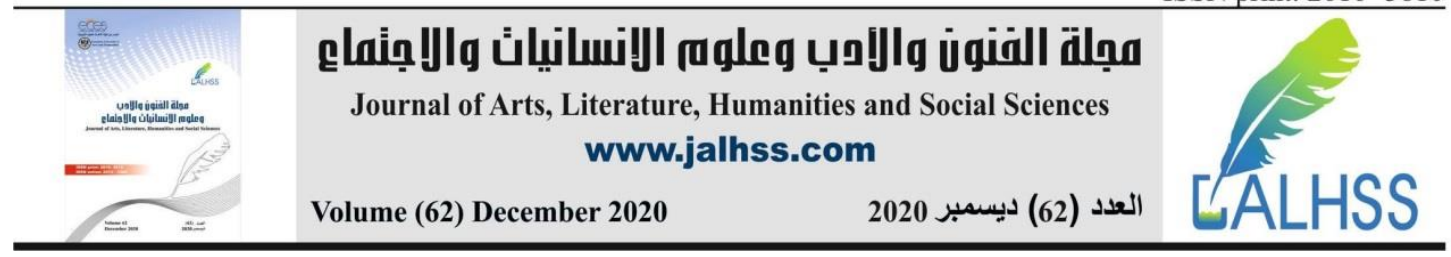

Psychometric properties of the test

\section{1- The test is validated}

Apparent honesty is indicated by his ability to measure what was prepared for him (Dawood and Anwar Hussein, 1990, p. 118 .(To find out the virtual honesty of the elements of the scale, has been submitted to a group of experts specializing in the measurement and evaluation and teaching methods, a total reached 10, an arbitrator to assess the validity of paragraphs to measure characteristic, and was relying on a standard (80\%) standard to accept the paragraph, and based on the previous standard was Acceptance of all paragraphs of the scale.

\section{2- Stability of the test}

The scale was applied to a stability sample of (50) male and female students and the stability of the scale were calculated in more than one way. By the method of application and re-application, the scale obtained a stability $(0,82)$ and by the method (Fakronbach) the scale obtained a stability $(0,83)$

\section{Sixth: applying the final experience}

After verifying the research procedures by preparing research tools and verifying the equivalence of the two groups, and the researcher's reassurance of the accuracy and environment of the experiment, the (Gracha) model was applied to the experimental group while the control group was studied by the lecture method.

\section{Seventh: Post-test}

After the researcher completed the research procedures and applied the Garacha model and the traditional method on the experimental and control groups, the skillful thinking scale was applied to both groups to demonstrate the effect of the model on developing the skillful thinking of the experimental group.

\section{Eighth: Statistical Means:}

The researcher used the following statistical methods in processing the data

1. The arithmetic mean

2. Standard deviation

3. Test $(\mathrm{t})$ For two independent samples for equivalence and hypothesis verification

4. Alpha Cronbach for persistence

\section{The fourth chapter}

\section{Research results}

\section{The research hypothesis states}

There are no statistically significant differences between the mean of the experimental group that studied the (Gracha) model and the average of the control group that studied the method of lecturing in the physiology course in the post application, and until the researcher verified the validity of this hypothesis, the scale was applied again to the two groups (experimental and control (after Finalizing the research procedures and to identify the extent of the differences between the two groups, the Ttest was used for two independent samples and the results were as shown in the following table: 


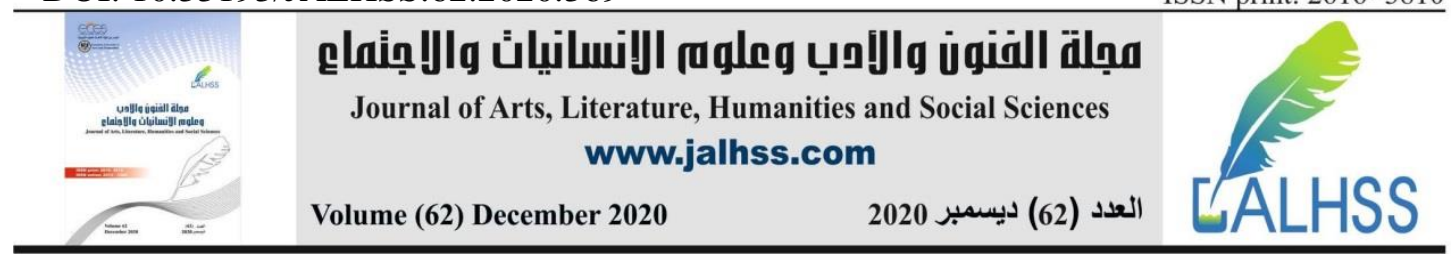

Table (6) Comparison between the experimental and control group in the post application

\begin{tabular}{|c|c|c|c|c|c|c|c|}
\hline \multirow{2}{*}{ Judgment } & \multirow{2}{*}{$\begin{array}{c}\text { Indication } \\
\text { level }\end{array}$} & \multicolumn{2}{|c|}{ Value -t- } & \multirow{2}{*}{$\begin{array}{c}\text { standard } \\
\text { deviation }\end{array}$} & $\begin{array}{c}\text { Arithmetic } \\
\text { mean }\end{array}$ & the number & the group \\
\cline { 3 - 3 } & & Tabular & Calculated & & & \\
\hline \multirow{2}{*}{ Function } & 0.05 & 2.02 & 6.857 & 1.333 & 113.75 & 20 & $\begin{array}{c}\text { Experimenta } \\
1\end{array}$ \\
\cline { 7 - 9 } & & & & 0.821 & 91.40 & 20 & Control \\
\hline
\end{tabular}

Through the previous table, it becomes clear to the researcher that the calculated $\mathrm{T}$ value reached (6.857), which is greater than the tabular $\mathrm{T}$ value of (2.02). This result confirms the existence of clear and statistically significant differences between the experiment and the control groups, and these differences are in favor of the group with the largest average, which is the experimental group. This leads us to reject the null hypothesis and accept the alternative hypothesis, which indicates the existence of an effect of (Gracha) model in the development of cunning thinking among students of the Medical Institute in Physiology. This result is consistent with the results of previous studies that confirmed the existence and effectiveness of the Gracha model in developing achievement or thinking skills. The study (Khaled et al., 2013: 6) confirmed the evidence of a clear effect of the Gracha model on students 'academic achievement. In the same direction, the study pointed to Ted Khan \& Iqbal, 2016: P29 The effect of this model in raising students' performance in courses The researcher indicates that this model has a clear advantage in emphasizing the applied results through the development of skillful thinking among the students of the experimental group that takes into account the students' styles (independent, avoidance, cooperative ...) in the institutionalization process that allows each student to learn according to what He desires it, or what he is inclined to.

\section{Conclusions}

Based on the previous results, the researcher can draw the following conclusions:

1. The (Gracha) model has no clear effect on the development of skillful thinking among students of the experimental group on physiology among students of the Medical Institute.

2. The experimental group that was studied according to the Gracha model outperformed the control group that received the scientific material by the lecture method of the physiological subject at the Technical Medical Institute.

\section{Recommendations}

Based on the previous conclusions, the researcher recommends the competent authorities with the following:

1. Working to establish workshops and training courses for physiotherapy teachers in medical institutes in Iraq in order to raise their level of knowledge, ability and skills in dealing with these modern models of teaching

2. Emphasis on the use of modern strategies, methods and models in teaching scientific subjects, as they require understanding, analysis, synthesis, and higher mental abilities more than memorization and indoctrination.

3. Work on developing school curricula to conform to modern teaching models. 


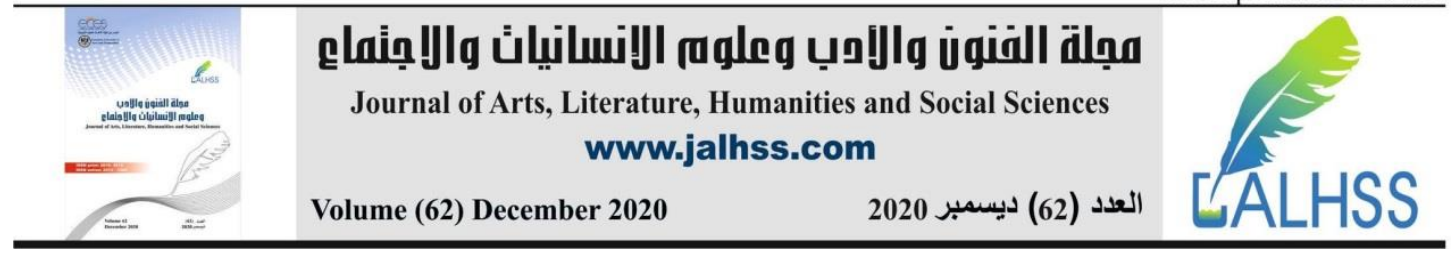

4. Procedures for other studies on the effect or effectiveness of the Gracha model in other study subjects and stages.

\section{The proposals}

1. Conducting a study entitled (Effectiveness of the Gracha model and the CAP model in the achievement of students of the Technical Medical Institute in the physiological subject and the development of their attitudes towards the subject.

2. Conducting a study on (building an educational program based on the Gracha model in order to develop inferential thinking among middle school students in the subject of chemistry)

By reviewing previous studies, the researcher can discuss them through her goal, as most of them were applied to university and institute students, which confirms the effectiveness and impact of this model on primary and higher university students and we note that this model has a clear effect in raising the level of thinking or students 'performance in achievement. The researcher believes that this is the main reason that on its impact brother Ta rate model for the application of the Institute.

\section{References}

1. Al-Ashqar, Faris Ratib (2011): Philosophy of Thinking and Theories in Learning, First Edition, Zahran for Publishing and Distribution, Amman.

2. Jaljul, Nasra (2013) Instruction Manual for Learning Styles Scale. Cairo: major libraries.

3. Al-Hijazi, Medhat Abd Al-Razzaq (2012): A Dictionary of Psychology Terms Arabic - English - Arabic, Dar Al-Kotob Al-Ulmiah, Beirut.

4. Khalil Al-Harbi (2012): Building a tool for measuring the learning styles of university students using exploratory factor analysis. Umm Al-Qura University Journal for General Education, Volume (4), Issue (2).

5. Al-Khalili, Amal Abd al-Salam (2005): The Child and Thinking Skills, First Edition, Dar Al-Saffar for Printing and Publishing, Amman.

6. Daoud, Aziz Hanna and Anwar Hussein Abdul Rahman, 1990 AD, Curricula for Educational Research, Dar Al-Hikma for Printing, Publishing and Distribution, Baghdad.

7. Al-Zobaie, Abdul-Jalil and Al-Ghannam, Muhammad Ahmad, 1981, Research Methods in Education, Second Edition, Baghdad University Press.

8. Zaitoun, Hassan Hussein (2003) Teaching Thinking, A World of Books, Cairo.

9. Zaitoun, Ayesh Mahmoud, 1999 AD, Methods of Teaching Science, Third Edition, Dar Al Shorouk Publishing and Distribution, Amman, Jordan.

10. Salem Mahmoud Yahya (2012): Psychology of Meaning and Application, First Edition, Arab Group for Training and Publishing, Egyptian Book House for Publishing and Distribution, Cairo.

11. Al-Sorour, Nadia Hayel (2005): Teaching Thinking in School Curricula, Wael House, Amman.

12. Al-Shuwaiqi, Abu Zaid (2004): The preferred learning styles of secondary school students and their relationship to gender and achievement level. Journal of the Faculty of Education, Tanta University (33), number 1. 


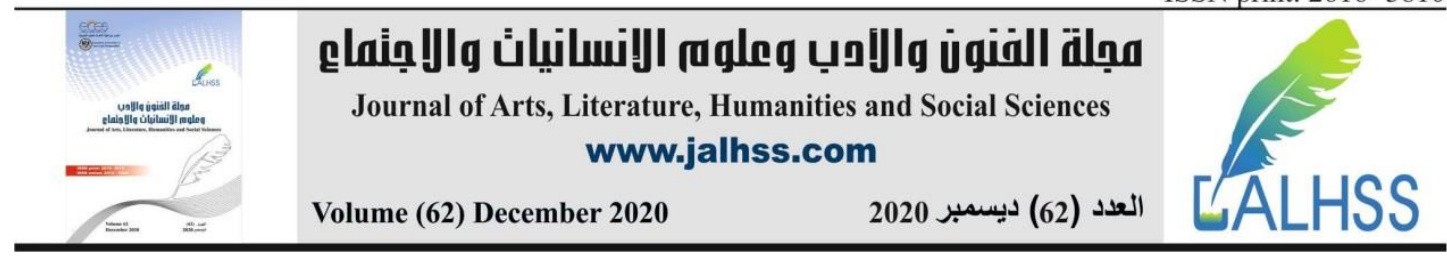

13. Al-Saffar, and Faih Muhammad Ali (2011): Skill and its relationship to cognitive preference and ability to solve problems among university students, PhD thesis (unpublished), College of Education, Ibn Al Haytham, University of Baghdad.

14. Damour, Muhammad Muslim Khalaf (2008): The relationship of learning styles prevailing among students of Damour universities in southern Jordan to academic achievement and self-efficacy, doctoral thesis, unpublished, University of Jordan, Amman., Jordan.

15. Zahir, Khaled Salman (2009): The effect of using a generative learning strategy in addressing alternative perceptions of some mathematical concepts among eighth grade students (unpublished master's thesis), College of Education, Islamic University, Gaza.

16. Aziz and Hatem Jassim and Mahdi Maryam Khaled (2015): Methodology and Reflection, First Edition, Al-Radwan Publishing and Distribution House, Jordan.

17. Attia, Mohsen Ali (2010): Metacognitive Strategies for Reading Comprehension, Madar Al-Mankhil Publishing, Amman.

18. Odeh, Ahmad, 2002, Measurement and Evaluation in the Educational Process, Fifth Edition, Dar Al-Amal, Amman, Jordan.

19. Odeh, Ahmad and Malkawi, Fathi, 1987, Basics of Research in Education and Human Sciences, First Edition, Al-Manar Library, Zarqa, Jordan.

20. Mahmoud Salah El-Din Arafa (2006): Think Without Borders, Contemporary Educational Visions in Teaching and Learning Thinking, The World of Books for Publishing and Distribution, Cairo.

21. Nofal, Muhammad Bakr, Al-Rimawi, Mahmoud Odeh (2010): Practical Applications in the Development of Thinking in the Habits of Mind, Second Edition, Dar Al-Masirah for Publishing and Distribution, Amman.

22. Nofal, Muhammad Bakr, Muhammad Qasim Sifan (2011), Merging Thinking Skills in Academic Content, First Edition, Dar Al-Masirah, Jordan.

23. Yousef, Suleiman Abdel Wahid (2011): Individual Differences in Mental Operations, First Edition, Dar Al-Masirah for Publishing and Distribution, Amman.

\section{Foreign sources}

1. Gracha, AF (1996). Teaching with a Style: A Guide to Reinforcement through an Understanding of Teaching and Learning Methods, Pittsburgh: Alliance Publishers.

2. Bicol Y. Gursel, M, Sulak, H; Ertken, II; Yazıc1, E; Dolger, D; Aslan, wai; Buyukkarci, K. (2010). Validity and

3. A Reliability Study of the Grasha-Riechmann Scale of Student Education. International Journal of the Humanities and Social Sciences, 5 (3)

4. Kumar, p. Kumar Smart, K. (2004). Evaluate the impact of teaching methods and information technology on students' learning styles. Journal of Issues in Media Science and Information Technology

5. Montgomery, SM \& Groat, LN (1998). Student learning styles and their implications for teaching. (CRLT Presentation Papers, No. 10). Center for Research in Learning and Teaching, University of Michigan. Retrieved from http: //www/crlt.umich.edu/occ10.html 


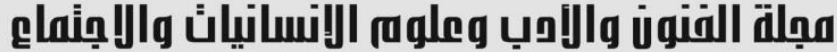 \\ Journal of Arts, Literature, Humanities and Social Sciences www.jalhss.com}

6. Isaac, N, and Awang, M. (2017). The relationship of student learning styles to achievement in history. The

7. International Journal of Invention of the Social and Human Sciences, 4 (3)

8. Khaled R. Mukhtar A. Fawzi, M. Qasim A. Don, Y. Abdul Saqour, N. Bonagan, F. Mohiuddin A. Ghazali, S. Rusley, M. Juke, S. (2013). Learning styles and academic achievements among students of science and arts streams. International Journal of Academic Research in Progressive Education and Development. 2 (2)

9. Khan, J. Iqbal, M. (2016). Effects of learning style on achieving distance learners. dialogue. 11 (3)

10. Arthur, L. Costa \& Bena, K. (2009) Habits of Mind Across the Curriculum Practical and Creative Strategies for Teachers Copyright (C) Association for Curriculum and Curriculum Development (ASCD)

11. Celtas, A. (2012) the effect of mathematical modeling on the level of creative thinking, The New Educational Review, 30 (4). 